\title{
Asset arbitrage and the price of oil th
}

\author{
Vipin Arora $^{\mathrm{d}, *, 1}$, Rod Tyers ${ }^{\mathrm{a}, \mathrm{b}, \mathrm{c}}$ \\ ${ }^{a}$ Research School of Economics, The Australian National University, Canberra, Australia \\ b University of Western Australia Business School, Perth, Australia \\ c CAMA, Australia \\ ${ }^{\mathrm{d}}$ U.S. Energy Information Administration, Washington D.C., USA
}

\section{A R T I C L E I N F O}

Article history:

Accepted 31 August 2011

\section{JEL classification}

E37

F47

Q43

Keywords:

Oil price

Arbitrage

Two regions

Dynamic model

Endogenous

Interest rates

\begin{abstract}
A B S T R A C T
It is commonly understood that macroeconomic shocks influence commodity prices and that one channel for this is the link between interest rates, expected future asset returns and stock-holding. In this paper the link is extended to the petroleum market with the recognition that recorded stocks of oil comprise a small share of annual demand and that the parallel with storable commodities is the decision to produce the oil in the first place, as opposed to holding it in the ground as reserve. Oil reserves are then a key asset in producing countries, which is arbitraged against financial assets. Thus, when the yield on financial assets falls, retaining oil reserves becomes more attractive to producing countries, which then have less incentive to accommodate demand rises, and so the oil price rises. This perspective on oil pricing is modeled in a dynamic multi-region general equilibrium framework in which regional households manage portfolios of assets that include oil reserves. When the model is calibrated to match observed data over two decades, simulation results indicate that asset arbitrage made a large contribution to the high pre-GFC oil price.
\end{abstract}

Published by Elsevier B.V.

\section{Introduction}

This paper looks at the macroeconomic factors behind the rapid oil price rise of the 2000s. Specifically, it models a producer's supply decision in the face of changing interest rates. Research suggests that a relationship between oil prices and interest rates does exist and is also important. Mabro (1998) and Barsky and Kilian (2004) have argued that over the medium-run, interest rates will impact producer extraction and investment decisions. Both Akram (2009) and Frankel (2006) find evidence of a negative relationship between interest rates and the level of oil prices.

The links between commodity prices and macroeconomic performance have been reviewed extensively by Kilian (2008), among others. Mabro (1998) and Barsky and Kilian (2004) have singled out the link with asset yields in particular, and Frankel (2006) and Akram (2009) have shown that it has an inverse association with the price. In the markets for storable commodities this link works through the bond yield as the opportunity cost of the funds tied up in stored

\footnotetext{
We have benefitted greatly from the comments and suggestions of Tim Kam, Junsang Lee, Richard Heaney, Chris Jones, Aki Asano, Warwick McKibbin, Paul Chen, Pedro Gomis Porqueras, Yiyong Cai, Hyejin Park, Mark Horridge, Peter Dixon, Dale Henderson, and Ngo Van Long.

* Corresponding author.

E-mail address: vipin.arora@eia.gov (V. Arora).

1 The analysis and conclusions expressed here are those of the authors and not necessarily those of the U.S. Energy Information Administration.
}

commodities. In this paper the link is extended to the petroleum market with the recognition that recorded stocks of oil comprise a small share of annual demand (United States Energy Information Administration, 2011). The parallel with storable commodities is the decision to produce oil in the first place, as opposed to holding it in the ground as a reserve. Oil reserves are then a key asset in producing countries, which can be arbitraged against financial assets. Thus, when the yield on financial assets falls, retaining oil reserves becomes more attractive to producing countries, which then have less incentive to accommodate demand rises, and so the oil price rises.

It has long been understood that changes in interest rates alter oil prices through producer extraction decisions if oil in the ground has value (Hotelling, 1931). Oil reserves can have value either because of scarcity or because production capacity is fixed in the short term. Dynamic global models accounting for this behavior are uncommon but include that by Arora (2011), which incorporates oil reserves as a financial asset. The results of that study show that the inclusion of the oil reserve asset greatly improves the precision with which the oil market can be simulated. Yet alternative financial assets backed by physical capital were excluded from that study and so asset arbitrage is unavailable.

This paper uses a two-region framework in which the focus is on arbitrage between multiple assets in the presence of oil producer monopoly power and open capital accounts. The problem of the collective household of the oil exporting region is one of choosing the rate of extraction so that the rate of return on oil in the ground matches the yields on the financial assets in its portfolio, namely 
bonds issued at home and abroad to finance physical capital accumulation. Deterministic simulations are used and the focus is on the price of oil in the lead up to and after the global financial crisis.

Simulation results from the model show that a fall in interest rates can lead to an increase in the price of oil. This occurs because producer extraction decisions are sensitive to the level of interest rates, so any change in these rates will feedback to prices through the supply-side. Counterfactual simulations also assign a large role in the price rise for falling interest rates even when related to increased demand. The results suggest that declining yields on financial assets can explain a large portion of the 2003-2008 price rise. The next section reviews the stylized facts and the elemental evidence for the demand growth and asset arbitrage hypotheses. Section 3 then introduces the model to be used and Section 4 describes the simulation results. Conclusions are offered in Section 5.

\section{Oil prices, the production shortfall and financial asset yields}

The period 2004-2007 saw the largest spike in oil prices since the 1970s (Fig. 1). The most common explanation for the price spike is that it is a fundamental consequence of an acceleration in global demand, due to growth surges in China and India, that was not accommodated by growth in oil production. The comparatively sluggish oil supply growth during the period is evident from Fig. 2. Strikingly, OPEC production actually slows in 2004, and falls beginning in 2005. This is the same period when the rate of growth in oil prices accelerates, as shown in Fig. 3.

A related story is a shortage of OPEC spare production capacity. This is largest in Saudi Arabia, which has historically used it to help offset the effects of demand shocks (Hamilton, 2009). As Fig. 4 shows, OPEC spare capacity also fell during this period, leaving Saudi Arabia the only member with a significant surplus (United States Commodity Futures Trading Commission, 2008). That this contributed to the spike is undisputed. Yet it is widely understood that the magnitude and speed of the price rise requires further explanation (Hamilton, 2009). For one thing, beginning in 2004, Saudi Arabian spare capacity actually rose, precisely at the time Fig. 3 shows the oil price rise began to steepen. For another, yields on financial assets had fallen since the 1980s which must have made holding back production a comparatively attractive option. Standing against the asset arbitrage hypothesis, however, is that the price spike occurred over a few short years while the yields on financial assets had been trending down for more than two decades.

To examine the asset arbitrage hypothesis more closely, note first that the global market for long term securities is highly integrated. While there are premia between long term government bond yields, even within the OECD, these premia are stable through time and there is a high degree of co-movement. This is unlike short term interest rates, which are instruments of monetary policy and therefore follow country-specific shocks. It follows that long term rates indicate successive equilibria between global saving supply and investment demand. Moreover, yields on the majority of assets held in collective national portfolios are closely related to long bond yields and so these yields constitute the opportunity cost of holding back on oil production, just as they represent the opportunity cost of committing agricultural commodities to storage. Indeed, it is primarily long term US government bonds that are acquired by the Asian net saving countries and by the oil exporters, and so these represent the alternative asset to oil reserves for exporting countries. The path of the yields on these assets follows that of U.S. 10 year Treasury Notes, as indicated in Fig. 5.

The graph also shows the effects on long term nominal yields of the US-driven inflation of the 1960s, the more widespread inflationary response to the oil shocks of the 1970s, which hid declining and eventually negative real rates, and the eventual decline in inflation and inflationary expectations after the early 1980s. Of particular interest, however, is that even when the "great moderation" had wrung out inflation expectations during the 1990s, nominal and real interest rates continued on a downward path. This, we posit, was due to the dominance of East Asia in global growth after the early 1980s, combined with the fact that Asian households are net savers and their governments have been fiscally conservative. In short, we ascribe the "savings glut" hypothesis as a source of continuous downward pressure on long term yields in the period of interest. ${ }^{1}$

From the standpoint of oil exporting countries, and with particular reference to Saudi Arabia, which has the largest national reserves and the greatest production capacity, this long term decline in the yield on financial assets suggests a rising comparative rate of return on oil reserves. Under these circumstances, failure to accommodate demand growth in Asia during the first decade of the 2000s may have been entirely rational. Indeed, the question arises as to why the oil price was not rising continuously over the two decades. Although the trend of the oil price was upward throughout, as Fig. 3 shows, the subsequent spike may have been brought about as a catch-up phase due to the very low bond yields of that decade, following a period during which the oil price might have been kept low by political pressure for high Saudi production or the off-setting rises in non-OPEC oil production.

\section{The model}

Two regions are represented, with structure to approximate the Middle Eastern OPEC countries on the one hand and the rest of the world economy on the other, each with a collective household that supplies labor and shares ownership of firms. One sector is nontraded services, which is intensive in labor and is included to ensure that real exchange rate behavior is representative. Manufacturing is intensive in physical capital and, in each region its ownership is shared by the two regional households. The oil sector appears in both regions but is dominant in the first and it is intensive in exhaustible oil reserves. Agriculture is included to provide an additional sector bound to a specific factor, land. All sectors use intermediate inputs supplied by the other sectors, including oil, and the two regions trade in agricultural products, manufactures and oil.

Capital accounts are open but ownership is only shared in the physical capital used primarily in each region's manufacturing sector. The households save at exogenous rates and each year's new saving is committed to bonds issued by the two manufacturing sectors (following Pennings and Tyers (2008)) and to "buy back" of regional oil reserves (retention of oil in the ground). Regional households can only invest in their own oil reserves and so manage portfolios comprising manufacturing bonds from both regions and their own oil reserves. Their allocation across these assets depends on expected rates of return and assumes imperfect substitutability between them. Since the dynamics are deterministic, this limited substitutability between assets provides a reduced form representation of the information and risk considerations that underlie portfolio management decisions.

Goods and factor markets are perfectly competitive except that the balancing of rates of return between nationally owned oil reserves and bonds ensures that depletion rates are optimal. ${ }^{2}$ The oil exporting region therefore extracts rents from its oil trade through the collective household's control over net supply. Land is specific to

\footnotetext{
1 In 2007, the savings rate of the emerging world was almost $10 \%$ of GDP higher than its 1986-2001 average. Investment was up as well - in 2007, it was about $4 \%$ higher than its 1986-2001 average. The big drivers of this trend were "Developing Asia" and the "Middle East." Developing Asia saved 45\% of its GDP in 2007 - up from 33 to 34\% in 2002 and an average of 33\% from 1994 to 2001 (and 29\% from 1986 to 1993). It invested 38\% of its GDP in 2007, an average of between 32 and 33\% from 1994 to 2001. The Middle East also saved 45\% of its GDP in 2007 - up from $28 \%$ of GDP back in 2002 and averages of $25 \%$ from 1994 to 2001 and $17-18 \%$ from 1986 to 1993 . Investment was up just a bit - at 25\% of GDP in 2007 an average of 22\% from 1994 to 2001. See Setser (2008), Paradigms, Twenty Cent (2008). See also Chinn and Ito (2008).

2 This balancing is incomplete in the short run, of course, since the assets are imperfectly substitutable, and so the optimality is approximate.
} 
agriculture and unchanged in supply, and labor is mobile between sectors but not between regions. The dominant input to the oil sector is extraction from reserves, though it also uses labor and a form of specific capital the supply of which is exogenous.

The financial asset markets modeled do not include money - all prices and values are defined relative to a single global numeraire. Each region's portfolio manager has perfect foresight in forming expectations as to asset returns in the next period, although adaptive expectations are also available.

\subsection{Structure}

The Middle Eastern OPEC region $\left(R_{1}\right)$ is modeled as having only oil as a significant export, with imports comprising agriculture and manufactures. $R_{1}$ is small compared with the rest of the world $\left(R_{2}\right)$, which is a large and comparatively diversified but nonetheless dominantly a service economy.

\subsection{Production}

In both regions production is a standard constant elasticity of substitution (CES) nest, as illustrated in Fig. 6. At the highest level, value added is combined with intermediates. Then, among intermediates, oil is combined with a composite of those supplied by other sectors. This provides flexibility in the representation of production structure as between the two quite different regions. In particular, $R_{1}$ has a dominant oil sector within which the shares and substitution elasticities ensure the corresponding dominance of extracted oil in the production process.

\subsection{Consumption}

The collective household in each region derives income from domestic and foreign assets and labor use. It is price taking in its consumption choices, deducting saving at a fixed rate from its current income (GNP) and allocating the remainder to maximize a CobbDouglas utility function in final demands for generic products. Home varieties are then differentiated from imports via the conventional Armington (1969) assumption, for realistic intra-industry trade in agriculture and manufactures, though the parameters are chosen so that there is virtually no two-way trade in oil.

\subsection{Asset portfolios and investment}

Savings are committed to investment in a two-step process. First, the collective household in each region chooses between the acquisition of bonds, which define all claims over physical capital in the two manufacturing sectors, on the one hand and oil reserves on the other. Payments for oil take the form of denied extraction and hence lost revenue and income. In the second stage, the savings devoted to bonds are allocated between those issued by home and foreign manufacturers.

Consider first the choice between bonds and oil. Because the assets are not perfectly substitutable, due to risk considerations and preferential biases not modeled explicitly, the equilibrium rates of return are unequal at the outset. The collective household maximizes a CES composite of the portfolio returns, RT. For a given year, the expenditure of region $i$ on oil reserves is $R I_{i}$ and on generic manufacturing bonds is $B I_{i}$, the collective household's problem is:

$\max _{R I_{i}, B I_{i}} R T=\left(\tau_{r i} R I_{i}^{-\rho_{r i}}+\tau_{b i} B I_{i}^{-\rho_{r i}}\right)^{\frac{-1}{\rho_{r i}}}$

each period this is subject to:

$s_{i} G N P_{i}=R I_{i}+B I_{i}$
The elasticity of substitution between the two types of asset is $\sigma_{R B}=1 /\left(1+\rho_{r i}\right)$ and the weights, $\tau$, depend on preferential biases and expected rates of return on each asset, $r_{r i}^{e}$ for oil and $r_{b i}^{e}$ for generic bonds available to region $i$. The expected rate of return on bonds, of course is that on physical capital in manufacturing net of depreciation. Thus, we set $\tau_{r i}=\gamma_{r i}\left(r_{r i}^{e}\right)^{\lambda_{i}}$ and $\tau_{b i}=\gamma_{b i}\left(r_{b i}^{e}\right)^{\lambda_{i}}$, where the coefficients $\gamma$ represent preferential biases and the elasticities $\lambda$ indicate the power of "return seeking" in portfolio management - the elasticities of bias to expected rates of return.

Solving the maximization problem yields the allocations:

$R I_{i}=s_{i} G N P_{i}\left[\frac{\gamma_{r i}^{\sigma_{r i}}\left(r_{r i}^{e}\right)^{\lambda_{i} \sigma_{r i}}}{\gamma_{r i}^{\sigma_{r i}}\left(r_{i}^{e}\right)^{\lambda_{i} \sigma_{r i}}+\gamma_{b i}^{\sigma_{r i}}\left(r_{i}^{e}\right)^{\lambda_{i} \sigma_{r i}}}\right]$

and

$B I_{i}=s_{i} G N P_{i}\left[\frac{\gamma_{b i}^{\sigma_{r i}}\left(r_{b i}^{e}\right)^{\lambda_{i} \sigma_{r i}}}{\gamma_{r i}^{\sigma_{r i}}\left(r_{r i}^{e}\right)^{\lambda_{i} \sigma_{r i}}+\gamma_{b i}^{\sigma_{r i}}\left(r_{b i}^{e}\right)^{\lambda_{i} \sigma_{r i}}}\right]$

The investment in oil reserves, $R I_{i}$, is costless, and so equivalent to leaving the oil in the ground. Each region can only invest in its own oil reserves, however. ${ }^{3}$ If the price of oil is $p_{r i}$, the quantity of oil retained is:

$I_{r i}=\frac{R I_{i}}{p_{r i}}$

The savings devoted to bonds can be used to purchase both home and foreign issues. As in the case of the choice between oil reserves and bonds, these are imperfect substitutes and therefore yield different rates of return in any single year. To allocate saving between these bonds the region $i$ 's collective household chooses expenditure on home and foreign manufacturing bonds, $B_{i}$ and $B_{i}^{*}$, to maximize its composite rate of return on bonds, $r_{b i}^{e}$, in the same manner as for (1) and (2):

$\max _{B_{i}, B_{i}^{*}} \quad r_{b i}^{e}=\left(\theta_{i} B_{i}^{-\rho_{b i}}+\theta_{i}^{*}\left(B_{i}^{*}\right)^{-\rho_{b i}}\right)^{\frac{-1}{\rho_{b i}}}$

Subject to:

$B I_{i}=B_{i}+B_{i}^{*}$

Here again the weights, $\theta$, depend on the expected rates of return on the bonds issued in the two regions: $\theta_{i}=\phi_{i}\left(r_{i}^{e}\right)^{\lambda_{i}}$ and $\theta_{i}^{*}=\phi_{i}^{*}\left(r_{i}^{*}, e\right){ }^{\lambda_{i}}$. As before, the coefficients $(\phi)$ are bias parameters and the elasticities $(\lambda)$ indicate the power of "return seeking". Solving to maximize (6) yields demands in region $i$ for its own and foreign bonds:

$B_{i}=B I_{i}\left[\frac{\phi_{i}^{\sigma_{b i}}\left(r_{i}^{e}\right)^{\lambda_{i} \sigma_{b i}}}{\phi_{i}^{\sigma_{b i}}\left(r_{i}^{e}\right)^{\lambda_{i} \sigma_{b i}}+\left(\phi_{i}^{*}\right)^{\sigma_{b i}}\left(r_{i}^{*, e}\right)^{\lambda_{i} \sigma_{b i}}}\right]$

and

$B_{i}^{*}=B I_{i}\left[\frac{\left(\phi_{i}^{*}\right)^{\sigma_{b i}}\left(r_{i}^{*, e}\right)^{\lambda_{i} \sigma_{b i}}}{\phi_{i}^{\sigma_{b i}}\left(r_{i}^{e}\right)^{\lambda_{i} \sigma_{b i}}+\left(\phi_{i}^{*}\right)^{\sigma_{b i}}\left(r_{i}^{*, e}\right)^{\lambda_{i} \sigma_{b i}}}\right]$

The savings committed to bond investment in each region finance purchases of capital goods that add to the capital stock. ${ }^{4}$ In a manner standard in applied general equilibrium analysis, these capital goods are supplied by a specialized industry that forms a CES composite of manufactures and services.

\footnotetext{
${ }^{3}$ This is a key element of the incompleteness of financial markets in the model.

${ }^{4}$ Time to build is here just one period. Investment costs are not necessary given the damping effects that stem from the forward looking expectations and the imperfect substitutability.
} 


\subsection{Dynamics}

The principal source of dynamic behavior in the model is the accumulation of physical capital in the two regions. The stocks of physical capital follow convention:

$k_{i, t+1}=k_{i, t}\left(1-\delta_{i}\right)+I_{i, t}$

where investment, $I$, is determined by the bond sales explained in the previous section. The demands thus embodied are met by regionspecific capital goods industries that blend manufactures and services. In framing their portfolio decisions, and hence their annual bond purchases, the collective households form expectations over rates of return 1 year ahead. With perfect foresight in region $i$, the expected rate of return on home capital (net of depreciation) is the extra value of output earned in $t+1$ for a unit capital investment in $t$, net of depreciation. This depends on capital's expected marginal physical product in $t+1$, calculated from the CES nest summarized in Fig. 6. It also depends on region $i^{\prime} s$ price of manufactures in $t+1$, its depreciation rate and its composite price of capital goods in $t^{5}$ :

$r_{i, t}^{e}=\frac{p_{m_{i}, t+1} M P_{k_{i}, t+1}}{p_{k_{i}, t}}-\delta_{i}$

This is balanced against the expected rate of return on oil reserves:

$r_{r i}^{e}=\frac{p_{r i, t+1}^{e}-p_{r i, t}}{p_{r i, t}}$

The expected rate of return on oil reserves is the rate of return the producer can expect from holding a barrel in the ground, which is the expected rate of growth in its price. While the Middle East OPEC region's collective household exercises power in the oil market by taking production off the market, its producers are price taking. Given this, and that oil production requires no intermediate goods, the price of oil is the sum of unit payments to the factors of production, and the expected price is the expected payments to those factors.

Any changes to the oil price must necessarily work through changes to the prices (or expected prices) of each factor. In the case of the simulations below, oil price rises are often due to rises in payments to oil in the ground as opposed to a higher wage. This is because labor is mobile across sectors while oil in the ground is not. Thus restricting the amount of oil in the ground which can be used for production will raise its rate of return, which raises the oil price. This is exactly what happens when the rate of return on bonds falls in the simulations below.

The modeling software used is Gempack, which requires an initial solution for all endogenous variables in every year. The dynamic nature of the model makes it a complex process to construct a consistent multi-period baseline solution, or database. Moreover, because oil reserves are being depleted and physical capital is accumulating at different rates in the two regions, the baseline is not a steady state time path for the represented global economy. Codsi et al. (1992) offer a now standard approach to this problem when the baseline is a steady state. Since the presence of two dissimilar regions and resource depletion rules this out an alternative approach is required. The model is therefore solved as a single high-dimension non-linear simultaneous equations problem and the method of Wendner (1999) is used to construct a non-steady-state baseline projection. This method dictates that the static solution for the base year be extrapolated over the simulation horizon by adding slack terms to each dynamic equation and then running a simulation that shocks each slack term to zero, thus building a dynamic database that is consistent with the equations of

\footnotetext{
${ }^{5}$ An adaptive expectations alternative is included to allow for backward-looking expectations, though it is not used in this analysis.
}

the model and the base year data. The key experiment reported henceforth represents a simulated departure from this dynamic baseline.

The lack of any requirement that the baseline should be a steady state then makes it possible to simulate oil reserve depletion explicitly. So initial reserve volumes are depleted over time by extraction for oil production. Oil supply decisions by the competitive oil industry of each region are modified when the collective household, or government, chooses to "buy back" oil (or constrain depletion and supply) as part of its portfolio management. Global petroleum reserves are large in relation to annual extraction, however, and there are gradients in quality and extraction cost that cannot be represented in this analysis. For this reason we have chosen not to monitor the size of the oil reserve in either region explicitly. To represent the asset arbitrage behavior that parallels Hotelling (the drawing of oil resource yields and bond yields together through time), it is sufficient to have collective households with market power conducting portfolio "buy backs" along with oil production being constrained by fixed sector-specific capital and a resource stock that is large enough relative to annual extractions to be considered stable over the simulation interval. ${ }^{6}$

\subsection{Database}

The base year data includes detailed incomes and expenditures by product and region for the year $2001{ }^{7} R_{2}$, the "rest of the world" group, is larger in GDP by a factor of 45 and more diversified across production sectors. $R_{1}$, the Middle Eastern OPEC countries, on the other hand, has a saving rate larger than that of $R_{2}$ by a factor of 2.5. Initial shares and elasticities of substitution ensure that services are effectively non-traded between regions and the dominance of extracted oil in oil production is ensured via its large initial share in expenditure on inputs and a very low elasticity of substitution between extracted oil and other inputs and production factors. The key elasticities and other parameters draw on global dynamic modeling convention (Dimaranan (2006), Dixon and Rimmer (2002), and Dixon and Rimmer (2009)) or are conjectures the sensitivity of which is subsequently explored. They are listed in Table 1.

\section{Simulations and results}

The analysis requires the construction of a baseline simulation on the interval 1984-2007. This simulation offers an indication of the effects of economic growth in the period, combined with bond yield declines and expanded non-OPEC oil production, on the real oil price. To separate the savings glut from the other determinants, the baseline simulation is compared with a single counterfactual simulation in which there is no shift in the $R_{2}$ saving rate and real yields on $R_{2}$ bonds do not decline through time.

\subsection{Constructing the baseline}

The initial inter-temporal database, or baseline simulation, represents the two economies as growing at different rates due to differences in their rates of labor force and productivity growth, their different saving rates and the rise in non-OPEC oil production in $R_{2}$. Non-OPEC oil production is shocked on an exogenous trend that sees it rise by $20 \%$ over its 1984 level. The exogenous rates of labor force growth in the two regions are roughly equal at $2 \%$ per year United States Department of Agriculture, 2011. Industrial productivity growth rates are obtained via a closure choice in which industrial total factor productivity is made endogenous in each region while real GDP is exogenous. A similar approach is taken to the saving

\footnotetext{
${ }^{6}$ In fact, reserve stocks need not be modeled explicitly.

7 Data for the base year is from the GTAP 6 Database. The Middle Eastern OPEC countries are aggregated into $R_{1}$ and the rest of the world into $R_{2}$. Standard re-aggregation methods were used, yielding a balanced matrix of flows within and between the two regions, including financial flows and expenditures on intermediate inputs.
} 
rate in $R_{2}$. The initial saving rates are shown in Table 1 . That of $R_{2}$ is allowed to vary through time via a choice of closure that makes the $R_{2}$ saving rate endogenous and the real rate of return on $R_{2}$ bonds exogenous. This ensures that the baseline captures the decline in bond yields associated with the savings glut period (Fig. 5), which amounted to approximately $2.5 \%$ each year on average. ${ }^{8}$

A validation test of the model is to compare the baseline simulated path of the real oil price (as imported by $R_{2}$, deflated by the simulated $R_{2}$ consumer price index) to its recorded value. This is done for year on year changes in Fig. 7. From this it is clear that the simulated price is slightly high by comparison with the recorded one, which we see as a consequence of the absence from representation in our model of close energy substitutes, such as coal and natural gas. Strong substitution into these alternatives in the 1980s and 2000s, for such uses as power generation and home heating, took the edge off oil demand growth in a manner that would require a much more complex model to represent.

The volatility of the simulated series is similar to that of the actual one, with the two having standard deviations in annual percentage changes of $2.4 \%$ and $2.6 \%$, respectively. The correlation coefficient is a less inspiring -0.379 , though the model fits much better in the period after 2000 than for the series as a whole. This may suggest that the asset arbitrage channel in the model is a better representation during this period than before. Certainly, the trend toward financial globalization continued throughout the period and capital account flows were generally less obstructed toward the end of the period than earlier.

Fig. 8 shows the normalized changes in production under the baseline simulation. There is an initial drop in production, which lasts for nearly four periods, and then it begins to rise until the end of the simulation period. This drop is attributable to the sudden price rise, whereby producers restrict production by retaining more oil in the ground. This restriction occurs because the expected rate of return on oil has risen, raising its value as an asset, inducing less production. Production begins to rise after several periods due to increased demand. The initial reductions in demand are consistent with the increases in price shown in Fig. 9 for the baseline simulation as well.

These oil price and production responses are consistent with behavior in other sectors of the model as well. For example, in the manufacturing sector other things equal, a falling bond yield leads to less physical capital accumulation. This leads to less demand for manufactured goods in the production of investment goods. While we observe this behavior in the model, it is constrained to act via portfolio choices since each region's collective household saves at an exogenous rate.

\subsection{Separating asset arbitrage from demand growth effects}

We conduct this decomposition by constructing a counterfactual simulation. To do so, we first change the closures used in the baseline so that productivity shocks are exogenous at their baseline levels and the regional real GDP levels are endogenous. Real GDP growth in $R_{2}$ is then slower due to the absence of Asian savings. Similarly, the yield on $R_{2}$ bonds is rendered endogenous and the $R_{2}$ saving rate path exogenous. This time, however, there is no change to the $R_{2}$ saving rate through time, and so the $R_{2}$ bond yield does not follow the observed path. ${ }^{9}$ This greatly reduces the incentive for the market power possessing $R_{1}$ collective household to "buy back" oil or hold it in the ground. $R_{1}$ oil production therefore grows quicker, and so the path of the traded oil price shows significant differences.

The first difference is clear from Fig. 9, which shows the dynamics of the baseline and counterfactual oil prices. Volatility in the rate of change in the oil price is much reduced when the path of bond yields is smoother with the constant $R_{2}$ saving rate. This is to be expected given the asset arbitrage channel made explicit in the model but the

\footnotetext{
${ }^{8}$ The exogenous path of $R_{2}$ bond yields follows that of 10 -year US Treasury notes, as per Fig. 5.

9 The bond yield still falls as in the baseline, but at only half of the rate
}

volatility link shown is borne out by the empirical analysis of Akram (2009). The second difference is also clear from Fig. 9. The path of the counterfactual oil price is lower than the baseline, achieving a final level just under half of the baseline value. A falling expected bond yield increases the price of oil because oil and bonds are substitutes in the regional household's portfolio. This is encapsulated in the household's demand for bonds and the resource via Eqs. (3) and (4). These show that if the expected yields on home or foreign bonds fall, oil in the ground becomes a relatively more attractive investment for the household, all else equal. Purchases of oil for investment (holding oil in the ground) rise and purchases of bonds fall. This is equivalent to the oil producer restricting production, which raises the price of oil. Fig. 8 shows that in the counterfactual case oil production in the oil producing region does not fall over the simulation. This is consistent with a lower rise in the price of oil.

The results of Fig. 9 suggest that the demand forces driving up the oil price account for no more than half the simulated rise over the two decades. The remainder of that rise is driven by asset arbitrage in response to the declining trend in bond yields. The results therefore offer strong support for the incorporation of the asset arbitrage channel in models with endogenous oil prices.

\subsection{Sensitivity to asset substitutability}

The key parameter in the model is the elasticity of substitution in investment between oil reserves and bonds. This parameter governs the flexibility with which the collective households can rebalance their asset portfolios as between oil reserves and financial assets and therefore the extent of the conformity with Hotelling reserve depletion. It is unobserved, however, and so we test the robustness of the results to its value in $R_{1}$, the Middle East OPEC region. The value of this parameter in the analysis of the previous section is 2.5 . Here it is varied between 0.05 and 5.0. When these changes are made and the analysis repeated, the resulting prices are listed in Table 3. Their differences are small enough that they do not span the gap between the baseline and counterfactual oil price trajectories of Fig. 8. The power of the asset arbitrage channel therefore seems robust to this substitutability, suggesting that the key is in its incorporation rather than the precise value of the substitution elasticity used.

\section{Conclusion}

There is empirical evidence of a negative relationship between the levels of interest rates and oil prices though economic stories to explain this vary. To help explain this and to assess its role in oil price determination we introduce a global model with explicit arbitrage between assets that include oil reserves. Simulations show that a "savings glut" shock that causes real interest rates to decline does raise the oil price. This occurs because the collective household of the oil exporting region manages its asset portfolio so as to balance expected rates of return across assets. Since the rate of return on oil reserves is the expected rate of increase in the oil price between the current and the next year, a fall in the expected rate of return on other assets due to a savings shock requires a rise in the current oil price. This necessitates that production be held back. Alternatively, this can be seen simply as a reallocation away from assets expected to offer lower returns toward oil reserves.

Once this behavior is represented in the model it is possible to offer a simple decomposition. For this we use deterministic simulations to examine the rise in the oil price between the 1990s and 2008, which happens to coincide with both a surge in oil demand due to faster economic growth in Asia and a declining trend in global long term bond yields said to be due to a "savings glut". The results suggest that demand growth effects on the oil price are substantial but that the asset arbitrage effect is large as well. Indeed, as modeled, the baseline simulated real oil price increases between 1984 and 
2008, with demand growth explaining just under half this change and asset arbitrage the remainder. While the model's parameterization is elemental, sensitivity experiments applied to the substitutability of assets suggest that a significant contribution is made by asset arbitrage across a wide range of values for the key elasticity driving portfolio balancing behavior.

These results also highlight the importance of modeling the supply decisions of producers and governments of oil exporting countries when oil prices are made endogenous, while at the same time representing financial market behavior. There is no doubt that this enables the capture of important contributing factors in determining the price of oil. It also provides a more thorough approach to the links between macroeconomic behavior and oil supply than if only the demand side is modeled explicitly.

\section{Appendix A. Parameter Values and Figures}

Table 1

Key parameters.

\begin{tabular}{|c|c|c|c|c|}
\hline & $\mathrm{Ag}$ & Mf & Svc & Oil \\
\hline \multicolumn{5}{|l|}{ Elasticities of substitution } \\
\hline Production btw int goods and value added & 0.75 & 0.75 & 0.75 & 0.05 \\
\hline Value added btw factors and 1.0 & 1.0 & 1.0 & 0.1 & \\
\hline Intermediates btw oil and composite & 0.05 & 0.05 & 0.05 & 0.05 \\
\hline Composite intermediates btw good & 1.0 & 1.0 & 1.0 & 1.0 \\
\hline Int demand btw home and foreign & 5.0 & 5.0 & 5.0 & 100.0 \\
\hline Final demand btw home and foreign & 5.0 & 5.0 & 5.0 & 100.0 \\
\hline \multicolumn{5}{|l|}{ Regional parameters } \\
\hline Portfolio btw oil reserves and bonds & & & \multicolumn{2}{|r|}{2.5} \\
\hline Portfolio btw home and foreign bonds & & & \multicolumn{2}{|r|}{2.5} \\
\hline Capital goods prodn btw mfg and services & & & \multicolumn{2}{|r|}{2.5} \\
\hline Saving rate & & & & $R_{1}: 0.19, R_{2}: 0.08$ \\
\hline Depreciation rate & & & & 0.05 \\
\hline
\end{tabular}

Sources: Dimaranan (2006) and dynamic global modeling conventions assessed by Dixon and Rimmer (2009).

Table 2

Summary statistics for percent change in oil price.

\begin{tabular}{|c|c|c|c|}
\hline & Actual & Baseline & Counterfactual \\
\hline Mean & 0.00 & 0.048 & 0.041 \\
\hline Standard deviation & 0.026 & 0.024 & 0.012 \\
\hline Corr with actual & - & -0.379 & -0.238 \\
\hline
\end{tabular}

Table 3

Baseline simulation with alternative values of $\sigma_{r i} \%$ change over 1984.

\begin{tabular}{|c|c|c|c|}
\hline & $\sigma_{r i}=2.5$ & $\sigma_{r i}=0.05$ & $\sigma_{r i}=5.0$ \\
\hline Projected 2007 price & $439 \%$ & $453 \%$ & $413 \%$ \\
\hline
\end{tabular}

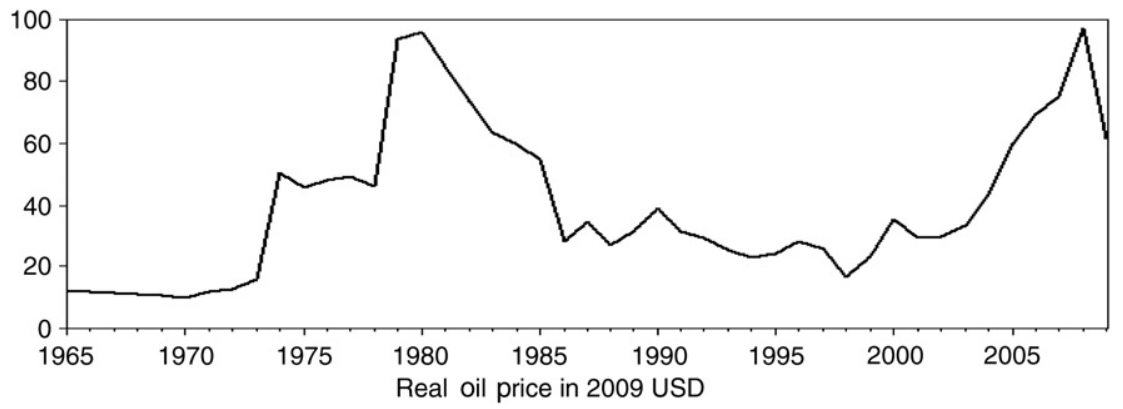

Fig. 1. Source: Statistical Review of World Energy 2010, BP. From 1965-1983 the price is Arabian Light posted at Ras Tanura. From 1983-2009 the price is Brent crude. 


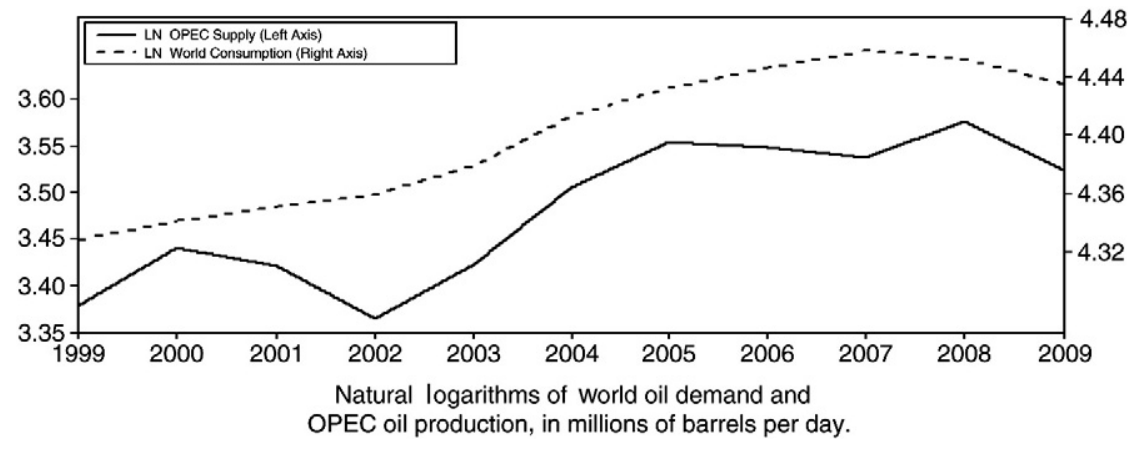

Fig. 2. Source: U.S EIA

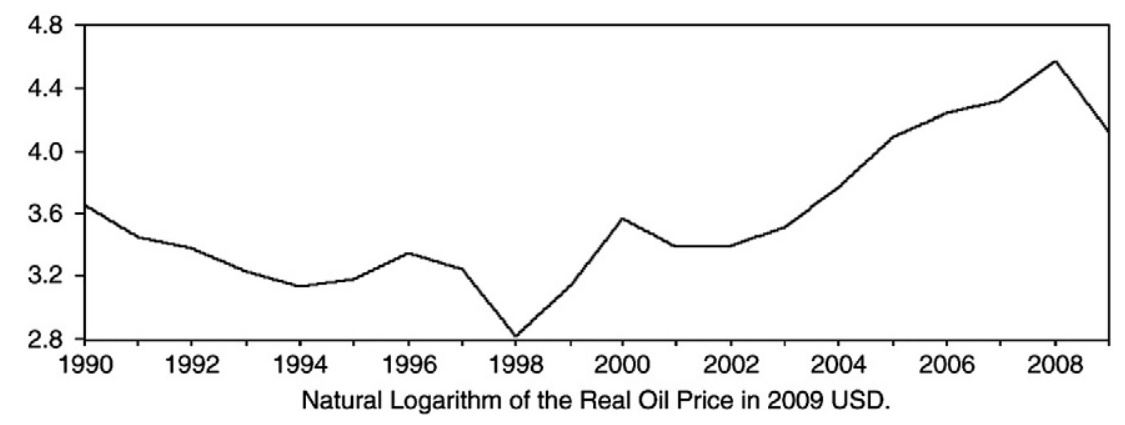

Fig. 3. Source: Statistical Review of World Energy 2010, BP. The price is Brent dated.

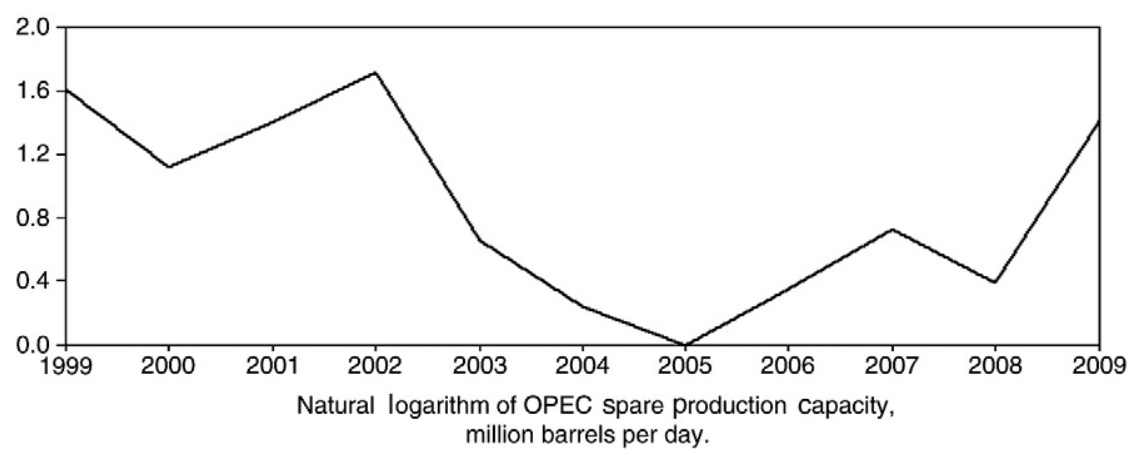

Fig. 4. Source: U.S. EIA

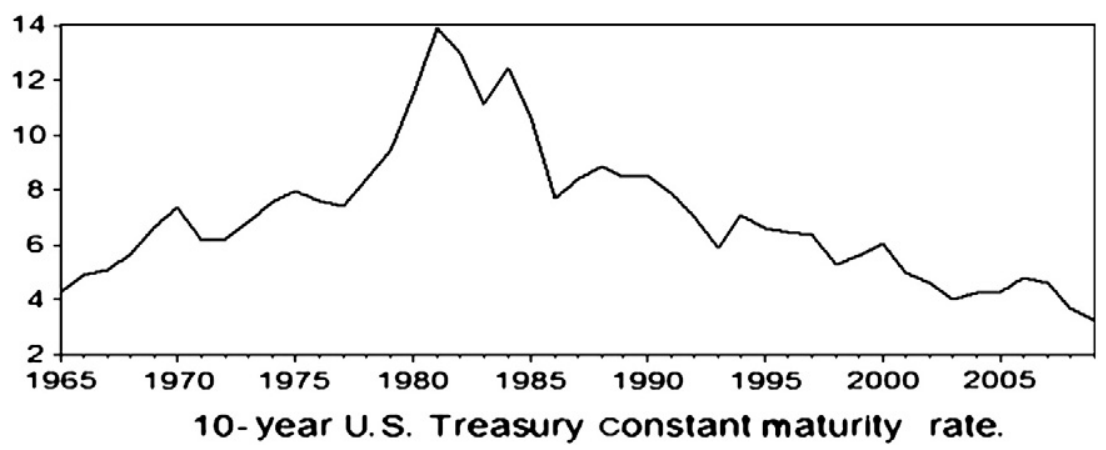

Fig. 5. Source: Fred. st. Louis Fed. 


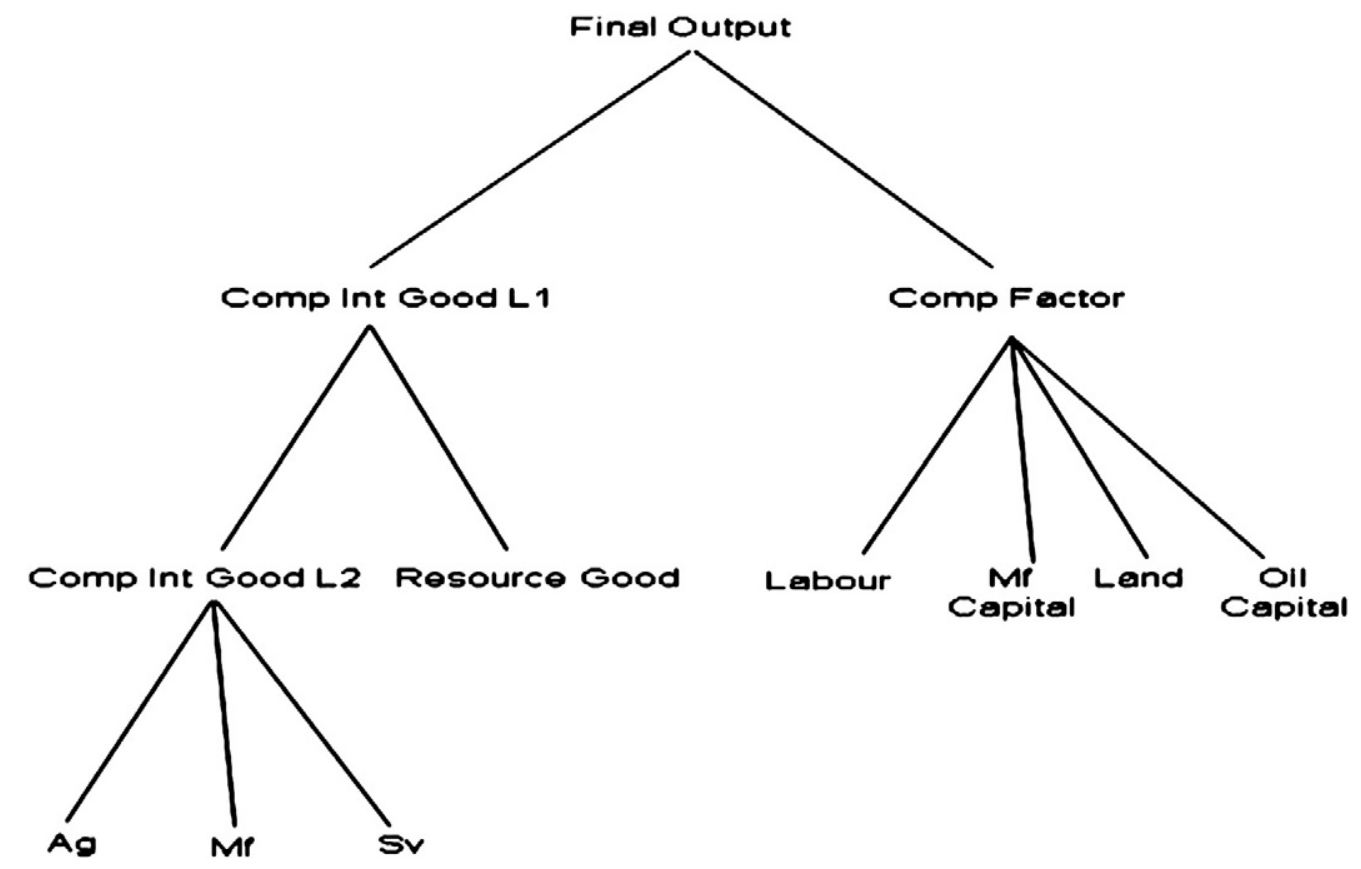

Fig. 6. Model structure.

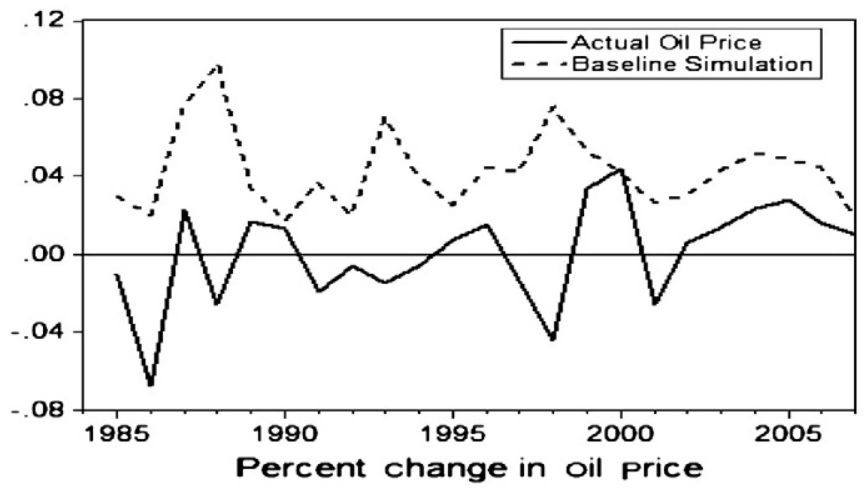

Fig. 7. Comparison of oil price changes.

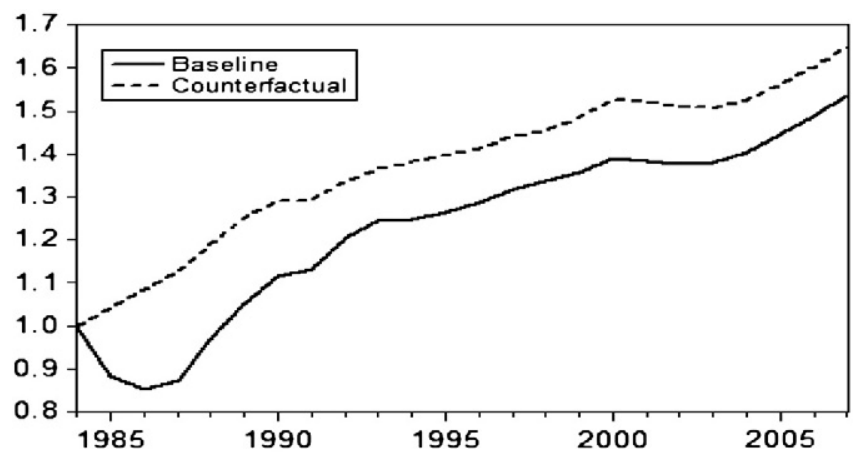

Simulated baseline and counterfactual oil production indices

Fig. 8. Normalized oil price changes.

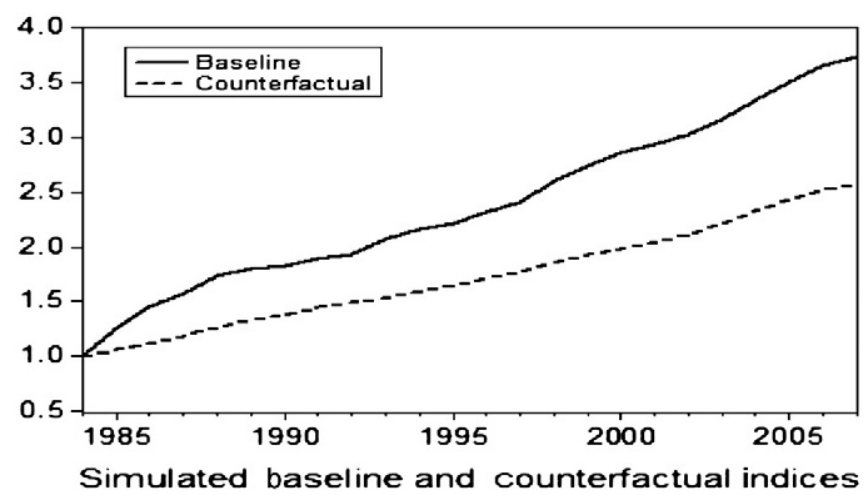

Fig. 9. Normalized oil price changes.

\section{References}

Akram, Farooq Q., 2009. Commodity prices, interest rates and the dollar. Energy Economics $31,838-851$.

Armington, P., 1969. A theory of demand for products distinguished by place of production. IMF Staff Papers 16, 159-176.

Arora, Vipin, 2011. Asset Value, Interest Rates, and Oil Price Volatility. The Economic Record 87, 45-55.

Barsky, Robert B., Kilian, Lutz, 2004. Oil and the macroeconomy since the 1970s. Journal of Economic Perspectives 18 (4), 115-134.

Chinn, M.D., Ito, H., 2008. Global current account imbalances: American fiscal policy versus East Asian savings. Review of International Economics 3, 479-498.

Codsi, George, Pearson, K.R., Wilcoxen, Peter J., 1992. General-purpose software for intertemporal economic models. Computer Science in Economics and Management $5,57-79$.

Dimaranan, B.V., 2006. Global Trade, Assistance and Production: The GTAP 6 Data Base. Center for Global Trade Analysis, Purdue University.

Dixon, Peter B., Rimmer, Maureen T., 2002. Dynamic General Equilibrium Modelling for Forecasting and Policy: A Practical Guide and Documentation of MONASH. North-Holland. 
Dixon, Peter B., Rimmer, Maureen T., 2009. Forecasting with a CGE model: does it work? General Paper G-198, Centre of Policy Studies. Monash University.

Frankel, Jeffrey A., 2006. The effect of monetary policy on real commodity prices. Working Paper 12713, NBER.

Hamilton, James D., 2009. Understanding crude oil prices. The Energy Journal 30 (2), 179-206.

Hotelling, Harold, 1931. The economics of exhaustible resources. Journal of Political Economy 39, 137-175.

Kilian, Lutz, 2008. The economic effects of energy price shocks. Journal of Economic Literature 4, 871-909.

Mabro, Robert, 1998. OPEC behaviour 1960-1988: a review of the literature. The Journal of Energy Literature 4 (1), 3-27.

Paradigms, Twenty Cent, 2008. Evidence on the Savings Glut Hypothesis. Retrieved from http://twentycentparadigms.blogspot.com. April.
Pennings, S., Tyers, Rod, 2008. Increasing returns, financial capital mobility and real exchange rate dynamics. The Economic Record 84, S157-S174.

Setser, B., 2008. The Global Savings Glut. March. Retrieved from Roubini Global Economics. United States Commodity Futures Trading Commission, 2008. Interim report on crude oil. Interim Report, US CFTC. July.

United States Department of Agriculture, 2011. International Macroeconomic Data Set Real GDP (2005 dollars) Historical. http://www.ers.usda.gov/Data/macroeconomics/ 2011. Retrieved in May 2011.

United States Energy Information Administration, 2011. Official Energy Statistics from the US Government. http://tonto.eia.doe.gov/dnav/pet/2011. Retrieved in May 2011.

Wendner, Ronald, 1999. A calibration procedure of dynamic CGE models for non-steady state situations using GEMPACK. Computational Economics 13, 265-287. 